\title{
Influence of Enhanced Carbon Crystallinity of Nanoporous Graphite on the Cathode Performance of Microbial Fuel Cells
}

Zhenyu Xing ${ }^{1+}$, Ningshengjie Gao ${ }^{2+}$, Yitong $\mathrm{Qi}^{1}$, Xiulei Ji ${ }^{1} *$ and Hong $\mathrm{Liu}^{2}{ }^{*}$

1. Department of Chemistry, Oregon State University, Corvallis, Oregon, 97331, United States.

2. Department of Biological and Ecological Engineering, Oregon State University, Corvallis, Oregon, 97331, United States.

$\dagger$ These authors contribute equally to this work.

\begin{abstract}
We have synthesized a porous graphite with a high degree of local crystallinity by adding copper powder as a catalyst into the magnesiothermic reduction of $\mathrm{CO}_{2}$. Furthermore, we revealed that the enhanced crystallinity of the carbon cathode catalyst promotes the electrochemical performance of microbial fuel cells under neutral $\mathrm{pH}$ conditions, which provides future guidance on the selection of carbon catalysts for microbial fuel cells.
\end{abstract}

*Corresponding authors: Tel: +1 541-737-6798, E-mail: david.ji@oregonstate.edu (Xiulei Ji); +1 541-737-6309, E-mail: liuh@engr.orst.edu (Hong Liu) 


\section{Introduction}

Microbial fuel cells (MFCs) represent an emerging technology that can directly extract energy from organic materials to generate electricity through microbial activities [1, 2]. Exoelectrogenic bacteria oxidize organic compounds and donate electrons to the anode, while the electrons are transferred through the external circuit and consumed by the reduction reactions on the cathode $[3,4]$. Chemicals, such as $\mathrm{Fe}(\mathrm{CN})_{6}^{3-}$ and permanganate have been used as terminal electron acceptors. However, these chemicals need to be either regenerated or replaced $[5,6] . \mathrm{O}_{2}$ is a ubiquitous electron acceptor, and air-cathode is the most commonly used cathode [7, 8]. Therefore, improving the performance of oxygen reduction reaction (ORR) has been a main focus in MFC cathode development, where the cathode catalyst is the most critical component in determining ORR performance. Metal-based catalysts, such as Pt/C, FePc, and CoTMPP, have demonstrated good performance in MFCs, but their high cost may prevent them from being used for certain practical applications, such as wastewater treatment and remediation [9-11]. Recently, carbon-based materials such as activated carbon, graphite granules, and graphene, have been demonstrated as promising cathode catalysts because of their comparable performance to metallic catalysts and potentially much lower cost [12-16]. 
Excellent carbon catalysts have following desirable properties: high specific surface area, suitable surface functional groups, high electronic conductivity and good stability [14, 17-23]. However, high specific surface area and superior conductivity typically are not possessed simultaneously by the same carbon structure. For example, graphite is highly conductive but is of very limited surface area; activated carbon could exhibit surface area up to $3000 \mathrm{~m}^{2} / \mathrm{g}$ but is hardly a good conductor due to its defective structure and high concentrations of $\mathrm{sp}^{3}$-bonding kinks [24]. Theoretically, a single layer of graphene will be an ideal candidate considering its high surface area of $2630 \mathrm{~m}^{2} / \mathrm{g}$ and its intrinsically high lateral conductivity; however, it is extremely challenging to utilize well-separated layers of graphene as a catalyst material due to its tendency of self-stacking back to graphite $[25,26]$. Alternatively, most studies in energy storage and conversion sectors have employed reduced graphene oxides (RGO) as active masses, which comprise "wrinkled-paper" like morphology [27-37]. Recently, such RGO materials, sometimes doped by other elements, have been investigated as MFC catalysts in neutral buffer electrolyte $[14,38$, 39]. However, RGO's structures are highly defective like activated carbons, inherited from its intense and corrosive processing by the Hummer's method, thus limiting its conductivity — a key property for an excellent catalyst in MFCs [40]. By far, a direct study on the influence of the carbon crystallinity, which determines the conductivity of carbon materials, on catalytic performance at neural $\mathrm{pH}$ is still lacking. 
In this contribution, we prepare a porous graphite where both high surface area and highly graphitic structure are realized in a single material, where we reveal that the increased graphitic crystallinity enhances the carbon's catalytic performance in MFCs. It is well known that highly graphitic structures are typically only obtainable by annealing graphitizable precursors under high-temperatures above $2000{ }^{\circ} \mathrm{C}$. Recently, we reported that magnesiothermic reduction reaction can convert gaseous $\mathrm{CO}_{2}$ into nanoporous graphite with a high surface area in a controllable manner by flowing $\mathrm{CO}_{2}$ over hot $\mathrm{Mg}$ or $\mathrm{Mg} / \mathrm{Zn}$ mixture [41]. Reduction by $\mathrm{Mg} / \mathrm{Zn}$ gives rise to a highly nanoporous graphenic carbon with a surface area above $1900 \mathrm{~m}^{2} / \mathrm{g}$ and uniform pore size distribution, which exhibits high-rate electrochemical properties in supercapacitors. With $\mathrm{Mg}$ alone as the reductant, the resulting carbon exhibits a good degree of long-range order along the $c$-axis and $a b$ planes, thus being fairly graphitic and graphenic, and exhibits a surface area of $829 \mathrm{~m}^{2} / \mathrm{g}$. A further challenge with respect to this reaction is to further enhance the crystallinity of such $\mathrm{CO}_{2}$-reduced carbons without compromising its specific surface area.

\section{Experimental Section}

\subsection{Preparation of porous graphite}

In a typical experiment, $1.5 \mathrm{~g}$ of $\mathrm{Mg}$ powder well mixed with $4 \mathrm{~g} \mathrm{Cu}$ powder (mole ratio $1: 1)$ was placed in an $\mathrm{Al}_{2} \mathrm{O}_{3}$ boat and heated in a tube furnace at $680{ }^{\circ} \mathrm{C}$ under a $\mathrm{CO}_{2}$ flow at $60 \mathrm{CCM}$ for 60 minutes. After the reaction, the black product was collected and stirred in $1.0 \mathrm{M} \mathrm{HCl}$ solution and $25 \% \mathrm{NH}_{3} \cdot \mathrm{H}_{2} \mathrm{O}$ solution at room 
temperature for 10 hours to remove $\mathrm{MgO}$ and $\mathrm{Cu}$, respectively. The mixture was then filtered and washed with deionized water several times. Finally, the product is dried at room temperature overnight.

\subsection{Characterization Methods}

X-ray diffraction (XRD) patterns were recorded by using a Rigaku Ultima IV Diffractometer with $\mathrm{Cu} \mathrm{K} \alpha$ irradiation $(\lambda=1.5406 \AA$ ). A $514 \mathrm{~nm}$ laser source was employed to collect the Raman spectra. The morphology was studied by field emission scanning electron microscopy (FESEM) using an FEI NOVA 230 high resolution SEM with an energy-dispersive X-ray (EDX) attachment. Transmission electron microscopy (TEM) images were recorded by FEI Titan 80-200 TEM. High-angle annular dark field scanning TEM (HAADF-STEM) measurements were carried out on an FEI Titan 80-200 microscope coupled with a HAADF detector and an EDX spectrometer. Nitrogen sorption measurements were performed on Micromeritics TriStar II 3020 analyzer.

\subsection{Electrode Preparation of ECs}

Porous graphite air cathodes for MFCs were fabricated by mixing $40 \%$ porous graphite and $60 \%$ carbon black with poly(tetrafluoroethylene) (PTFE). The total carbon loading is $8.75 \mathrm{mg} / \mathrm{cm}^{2}$. PTFE loading is $0.2 \mathrm{~mL} / \mathrm{g}$ carbon. The carbon/PTFE mixture was stirred and heated $\left(80{ }^{\circ} \mathrm{C}\right)$ in $100 \%$ ethanol to form a paste and applied on the carbon cloth substrate with cured $\left(340{ }^{\circ} \mathrm{C}\right)$ PTFE coatings on the air-facing side. These air cathodes were then pressed with a roller compactor. 


\subsection{Electrochemical Measurements}

A two-electrode cell configuration was employed to measure the electrochemical performance. Two nearly identical electrodes (by weight and size) were assembled in coin-type cells that use a filter paper $\left(\right.$ Whatman $^{\circledR}$ ) as the separator and a $6.0 \mathrm{M}$ $\mathrm{KOH}$ aqueous solution as the electrolyte. A VMP-3 multi-channel workstation was used for CV measurements, galvanostatic CD cycling and EIS tests.

Linear sweep voltammetry (LSV) and electrochemical impedance spectra (EIS) tests were conducted in three-electrode cell configuration, using Pt plates $\left(6.5 \mathrm{~cm}^{2}\right)$ as the counter electrode, the two types of porous graphite cathodes $(\mathrm{C}-\mathrm{Mg}$ cathode and $\mathrm{C}-\mathrm{Mg} / \mathrm{Cu}$ cathode) $\left(0.7 \mathrm{~cm}^{2}\right)$ as working electrode, and $\mathrm{Ag} / \mathrm{AgCl}$ (for $\mathrm{LSV}$ ) or Pt wire (for EIS) as the reference electrodes. The scan rate of LSV is $0.1 \mathrm{mV} / \mathrm{s}$ with voltage window ranged from 0.3 to $-0.2 \mathrm{~V}$ (vs. $\mathrm{Ag} / \mathrm{AgCl}$ ).

Microbial fuel cells were assembled following previous studies with $7 \mathrm{~cm}^{2}$ (working area) carbon cloth anode and $14 \mathrm{~mL}$ empty bed volume, except for using a small cathode $\left(0.7 \mathrm{~cm}^{2}\right.$ working area) to ensure the cathode limiting condition. The MFCs were fed with growth medium, which contains $\mathrm{KCl}, \mathrm{NH}_{4} \mathrm{Cl}, 50 \mathrm{mM} \mathrm{PBS}(\mathrm{pH}=7)$, minerals and vitamins solution, and $20 \mathrm{mM} \mathrm{NaAc}$ as carbon source. Fully grown anodes had been operated with repeatable power output for two months before being assembled with small cathodes in this study. 
MFC polarization curves and electrode potential curves were collected by reducing external resistance with an order of $600,500,400,300,250,200 \Omega$ at 30 min intervals. The stabilized voltage output and electrode potentials were measured using $\mathrm{Ag} / \mathrm{AgCl}$ reference electrode. The curves were collected at first batches after switching to a new cathode.

\section{Results and Discussion}

We are inspired by graphene sheet preparation by conducting chemical vapor deposition (CVD) of small organic molecules onto transition metal substrates, such as $\mathrm{Ni}, \mathrm{Pt}, \mathrm{Ru}, \mathrm{Ir}$, and $\mathrm{Cu}$ [42-46]. Transition metal substrates play a critical role in nucleating high-quality graphene sheets from the saturated solution with carbon dissolved in metal surface regions. Herein, we utilize one of the most widely employed graphene-forming substrates-copper mixed with $\mathrm{Mg}$ powder in the magnesiothermic reaction, attempting to increase the crystallintiy of the resulting porous graphite [45]. In a typical experiment, the mixture of $\mathrm{Mg}$ and $\mathrm{Cu}$ powder with an equal molar ratio is used to reduce gaseous $\mathrm{CO}_{2}$ under $680{ }^{\circ} \mathrm{C}$ for $1 \mathrm{hr}$. After removing $\mathrm{MgO}$ by diluted $\mathrm{HCl}$ solution $(1 \mathrm{M})$ and then $\mathrm{Cu}$ by concentrated $\mathrm{NH}_{3} \cdot \mathrm{H}_{2} \mathrm{O}$, the obtained carbon product is referred to as $\mathrm{C}-\mathrm{Mg} / \mathrm{Cu}$. As comparison, the carbon product by employing $\mathrm{Mg}$ alone is named as $\mathrm{C}-\mathrm{Mg}$.

We first characterized the crystalline structures of the resulting carbons by x-ray diffraction (XRD), where the degrees of order along $\boldsymbol{c}$-axis and $\boldsymbol{a} \boldsymbol{b}$ planes are revealed. By comparing the XRD patterns of $\mathrm{C}-\mathrm{Mg}$ and $\mathrm{C}-\mathrm{Mg} / \mathrm{Cu}$, it is evident that the addition 
of copper greatly increased the structural crystallinity along both directions. As for $\mathrm{C}-\mathrm{Mg}$, there exists a broad shoulder to the left of the (002) XRD peak, which is attributed to its non-graphitic substructures, whereas this shoulder is nearly eliminated in the XRD pattern of $\mathrm{C}-\mathrm{Mg} / \mathrm{Cu}$ (Figure 1a). In the pattern of $\mathrm{C}-\mathrm{Mg} / \mathrm{Cu}$, the $(002)$ peak slightly shifts to a larger angle, revealing a smaller d-spacing of $3.41 \AA$ in comparison to $3.43 \AA$ for $\mathrm{C}-\mathrm{Mg}$, thus being closer to $3.35 \AA$ of ideal graphite. Graphitic domain size along the $c$-axis also increases from $6.66 \mathrm{~nm}$ in $\mathrm{C}-\mathrm{Mg}$ to 12.51 $\mathrm{nm}$ in $\mathrm{C}-\mathrm{Mg} / \mathrm{Cu}$, as estimated by the Scherrer equation. The highly graphitic structure of $\mathrm{C}-\mathrm{Mg} / \mathrm{Cu}$ is corroborated by the images of high-resolution transmission electron microscopy (HRTEM), where ordered stacking of graphene layers exists for tens of nanometers in $\mathrm{C}-\mathrm{Mg} / \mathrm{Cu}$ compared to less than $20 \mathrm{~nm}$ for $\mathrm{C}-\mathrm{Mg}$ (Figure 2c and 2d). However, it is important to note that the resulting structure is not completely homogenous as there are less crystalline areas under TEM with smaller particle sizes. The existence of less dense portions would explain the large surface area of $\mathrm{C}-\mathrm{Mg} / \mathrm{Cu}$, which will be discussed later on. Furthermore, the graphitic degree can also be empirically characterized by a ratio of the (002) peak intensity and the background at the same diffraction angle, which is referred to as an R-value, first defined by Dahn et al [47]. A higher R-value suggests a higher-degree of order, where the R-value increases to 8.31 for $\mathrm{C}-\mathrm{Mg} / \mathrm{Cu}$ from 5.75 for $\mathrm{C}-\mathrm{Mg}$. 
(a)

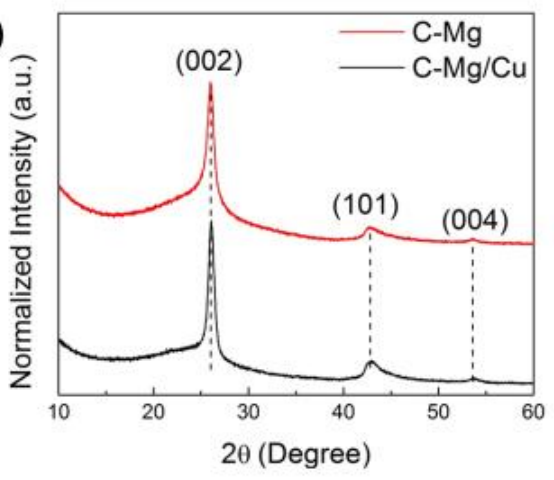

(c)

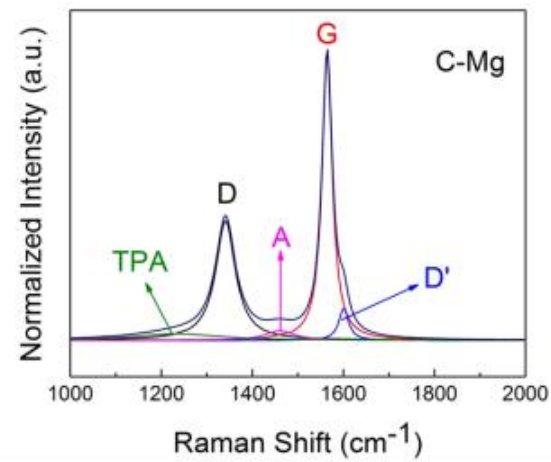

(b)

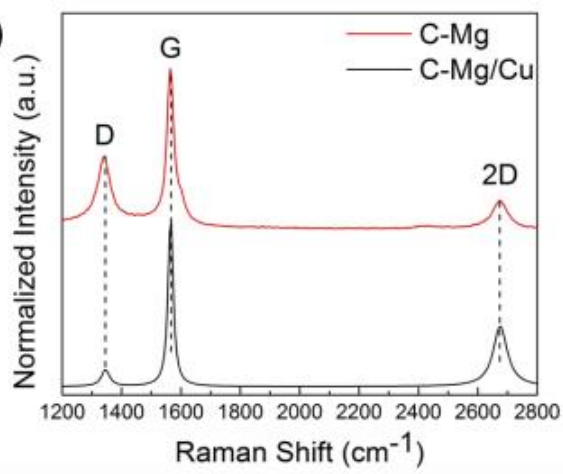

(d)

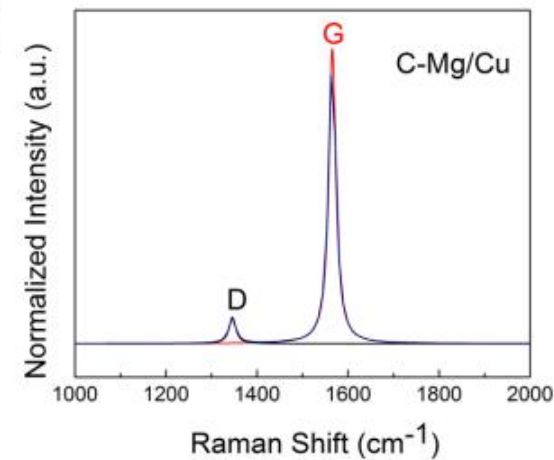

Figure 1. (a) XRD patterns of $\mathrm{C}-\mathrm{Mg}$ and $\mathrm{C}-\mathrm{Mg} / \mathrm{Cu}$, (b) Raman shift of $\mathrm{C}-\mathrm{Mg}$ and $\mathrm{C}-\mathrm{Mg} / \mathrm{Cu}$. Fitted Raman data and deconvolution into TPA (green), D (black), A (pink), $\mathrm{G}$ (red) and D' (blue) bands for $\mathrm{C}-\mathrm{Mg}$ (c) and $\mathrm{C}-\mathrm{Mg} / \mathrm{Cu}(\mathrm{d})$.

From Raman results (Figure 1b), it is evident that addition of $\mathrm{Cu}$ also renders the resulting carbon more graphenic. We fitted the experimental Raman spectra by using TPA, D, A, G and D' bands (Figure 1c,d) [48]. C-Mg/Cu only possesses D band and $\mathrm{G}$ band, whereas $\mathrm{C}-\mathrm{Mg}$ has all the above bands, where TPA band indicates the existence of transpolyacetylene-like structure, A band indicates the presence of point defects to $\mathrm{sp}^{2}$ graphenic planes, and $\mathrm{D}^{\prime}$ band indicates a defect-induced feature from the intra-valley double resonance scattering process [49]. The lack of the presence of TPA, A and D' bands together demonstrates that $\mathrm{C}-\mathrm{Mg} / \mathrm{Cu}$ comprises a 
more ordered local structure along $\boldsymbol{a} \boldsymbol{b}$ planes than C-Mg. Additionally, the intensity of $2 \mathrm{D}$ band of $\mathrm{C}-\mathrm{Mg} / \mathrm{Cu}$ is much higher than that of $\mathrm{C}-\mathrm{Mg}$, which confirms a highly crystalline structure of $\mathrm{C}-\mathrm{Mg} / \mathrm{Cu}$. As for the well-known $\mathrm{D}\left(1340 \mathrm{~cm}^{-1}\right)$ and $\mathrm{G}$ band $\left(1580 \mathrm{~cm}^{-1}\right), \mathrm{D}$ is attributed to photons' inelastic scattering with $\mathrm{A}_{1 \mathrm{~g}}$ breathing vibration mode of $\mathrm{C}_{6}$ rings in graphenic layers, where defects must be present to activate the $D$ band; $G$ band is assigned to the $E_{2 g}$ vibration of pairs of $\mathrm{sp}^{2}$-bonded carbon atoms. The intensity ratio between $\mathrm{D}$ band $\left(I_{D}\right)$ and $\mathrm{G}$ band $\left(I_{G}\right)$ has much to say about the graphenic degree of the carbons. Particularly, $I_{G} / I_{D}$ can be employed to estimate the lateral size, $L_{a}$, based on the following equation:

$$
L_{a}(n m)=\left(2.4 \cdot 10^{-10}\right) \cdot \lambda_{n m}^{4}\left(\frac{I_{G}}{I_{D}}\right)
$$

where $\lambda$ is $514 \mathrm{~nm}$ of the laser. As the G/D ratio increases from 2.14 to $9.90, L_{a}$ rises from $35.8 \mathrm{~nm}$ for $\mathrm{C}-\mathrm{Mg}$ to $165.8 \mathrm{~nm}$ for $\mathrm{C}-\mathrm{Mg} / \mathrm{Cu}[50]$.

The XRD (101) peaks can also indicate the lateral domain size of $L_{a}$, where by the Scherrer equation, it is calculated that $L_{a}$ increases to $10.75 \mathrm{~nm}$ from $7.68 \mathrm{~nm}$ in the presence of copper (Figure 1a). The discrepancy of $L_{a}$ values between Raman and XRD is well known, where the Raman results typically overestimate [51]. From both the XRD and Raman results, it is evident that $L_{a}$ significantly increases with $\mathrm{Cu}$ mixed in the reductant, which, indeed, results in a more graphenic carbon material. 
(a)

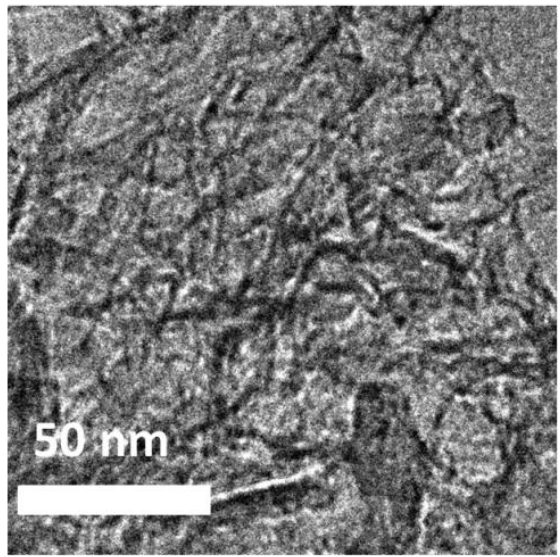

(b)

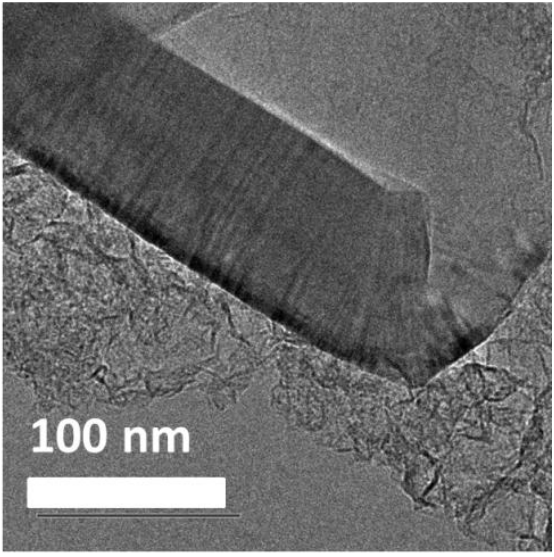

(c)

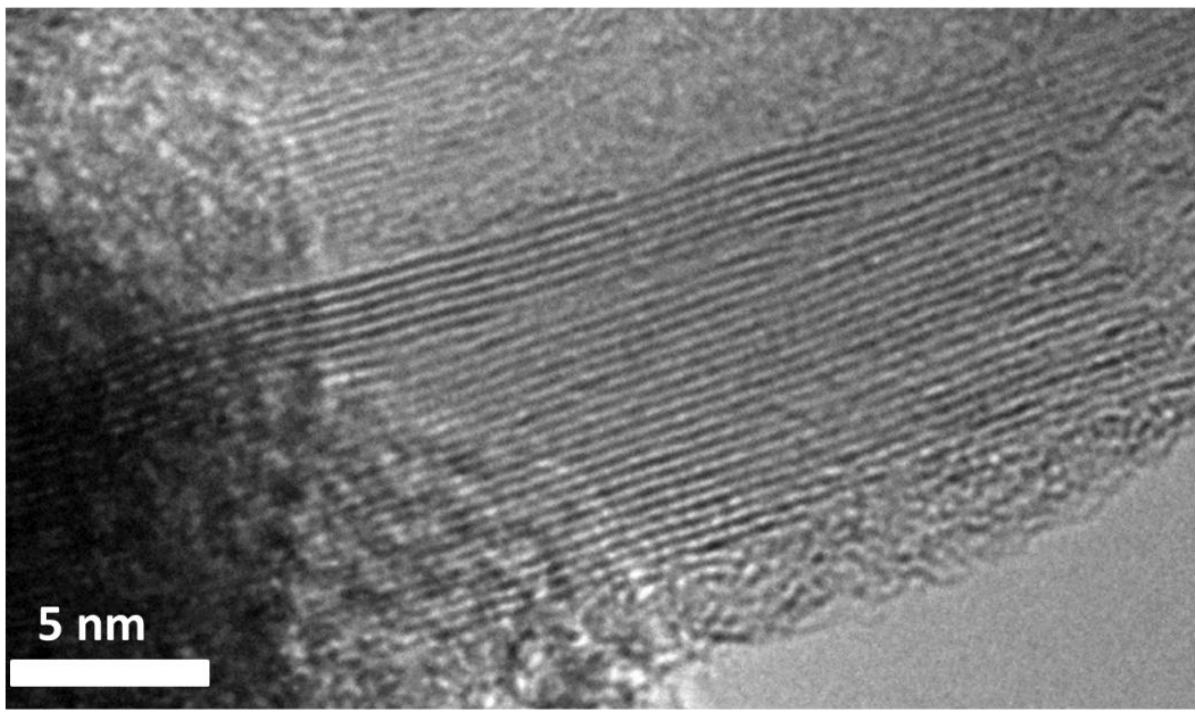

(d)

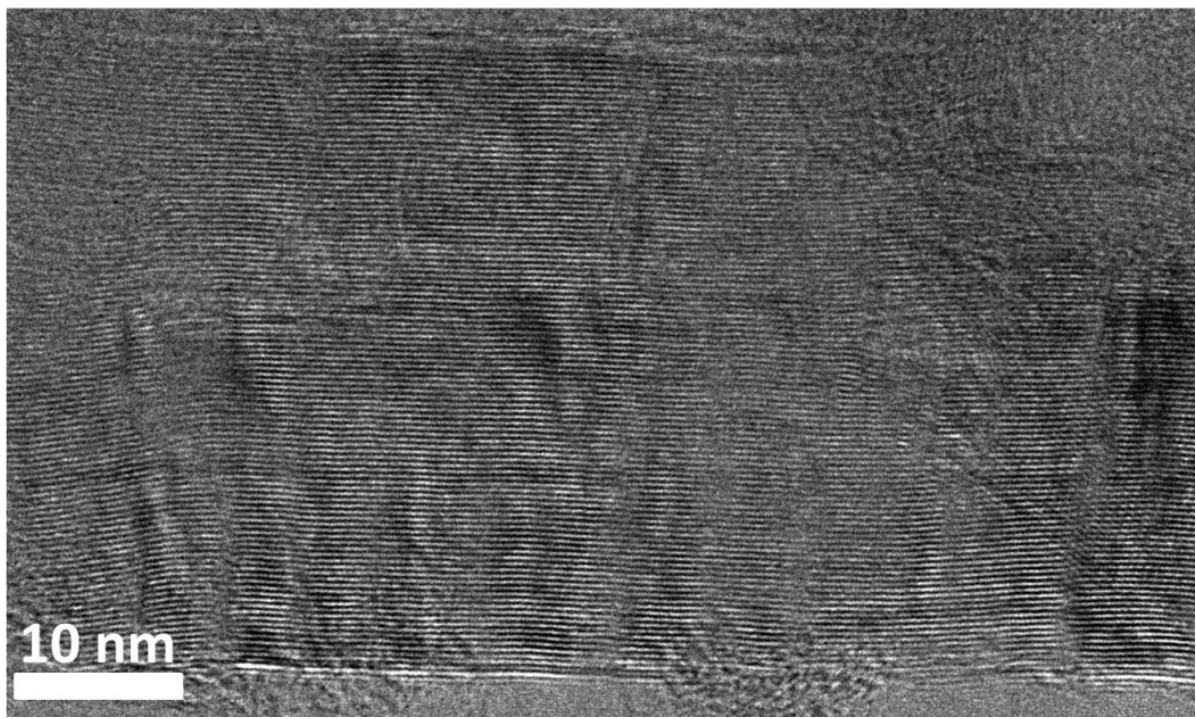

Figure 2. HRTEM image (a), (c) for $\mathrm{C}-\mathrm{Mg}$ and (b), (d) for $\mathrm{C}-\mathrm{Mg} / \mathrm{Cu}$. 
We further characterized the porosity properties of $\mathrm{C}-\mathrm{Mg}$ and $\mathrm{C}-\mathrm{Mg} / \mathrm{Cu} . \quad \mathrm{C}-\mathrm{Mg}$ and $\mathrm{C}-\mathrm{Mg} / \mathrm{Cu}$ exhibit Brunauer-Emmett-Teller (BET) specific surface area of $829 \mathrm{~m}^{2} / \mathrm{g}$ and $706 \mathrm{~m}^{2} / \mathrm{g}$, respectively, where $\mathrm{N}_{2}$ sorption isotherms of both $\mathrm{C}-\mathrm{Mg}$ and $\mathrm{C}-\mathrm{Mg} / \mathrm{Cu}$ show large hysteresis in the medium and high relative pressure ranges, indicative of a combined mesoporous and macroporous structure, as shown in Figure 3a. As shown in Figure 3b for the pore size distribution (PSD) results calculated by the Barrett-Joyner-Halenda (BJH) method, most pores in C-Mg are sized between 4 and $20 \mathrm{~nm}$, whereas $\mathrm{C}-\mathrm{Mg} / \mathrm{Cu}$ contains pores with more narrow PSD between 2 and $8 \mathrm{~nm}$.
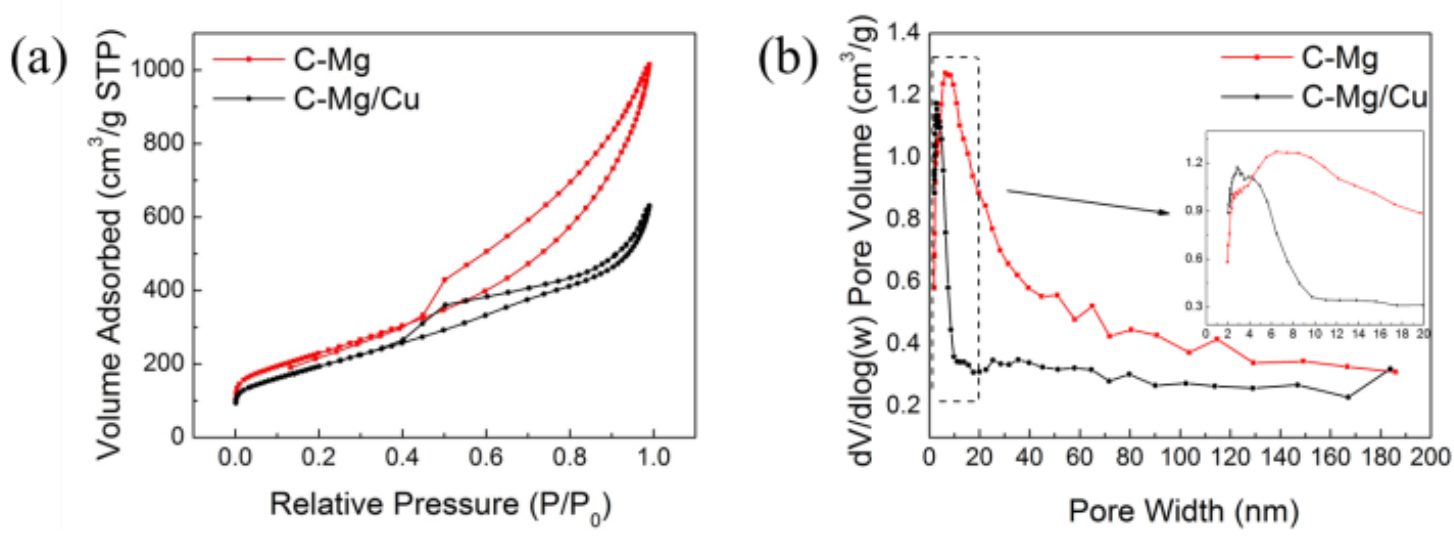

Figure 3. (a) Nitrogen sorption isotherms of C-Mg and $\mathrm{C}-\mathrm{Mg} / \mathrm{Cu}$. (b) Corresponding PSD of C-Mg and C-Mg/Cu.

We attempted to understand the function of $\mathrm{Cu}$ in enhancing the crystallinity in the graphitic/graphenic carbon during the magnesiothermic reaction. Note that copper is thermodynamically stable under pure $\mathrm{CO}_{2}$ at temperatures below $1100{ }^{\circ} \mathrm{C}$, which is confirmed by the resolved $\mathrm{Cu}$ peaks in the XRD pattern of the as-prepared product from the reaction between $\mathrm{CO}_{2}$ and magnesium and copper (Figure S1). Because 
the only controlling factor that differentiates the preparation of $\mathrm{C}-\mathrm{Mg} / \mathrm{Cu}$ and $\mathrm{C}-\mathrm{Mg}$ is with or without copper, respectively, the much higher degrees of order along the $c$ axis and $a b$ planes in $\mathrm{C}-\mathrm{Mg} / \mathrm{Cu}$ can only be attributed to the presence of copper in the reductant mixture. Considering its lack of being consumed, copper may play a catalytic role in the CVD process of carbon formation.

It is well known that carbon atoms can be dissolved into the surface phase of copper, it is very likely the graphene sheets are formed by "desolvating" from copper surface despite the fact that $\mathrm{CO}_{2}$ is the carbon precursor in this study instead of small organic molecules, e.g., $\mathrm{CH}_{4}$ [52]. We collected high angle annular dark field (HAADF) elemental mappings for the as-obtained sample after the magnesiothermic reaction (Figure 4). Interestingly, all the elements of $\mathrm{C}, \mathrm{Mg}, \mathrm{O}$, and $\mathrm{Cu}$ share almost identical shapes of distribution. It is worth pointing out that the shapes of $\mathrm{C}$ distribution is a little different from that of $\mathrm{Mg}, \mathrm{O}$, and $\mathrm{Cu}$, which may be due to the influence of the carbon film on the TEM grid. The insights from the HAADF results are two folded. First, the results confirm that the acting reductant is not pure $\mathrm{Mg}$ phase but a $\mathrm{Mg}-\mathrm{Cu}$ molten phase as the real local reaction temperature is above $1100{ }^{\circ} \mathrm{C}$, which is high enough to melt either intermetallic phases of $\mathrm{Mg}_{2} \mathrm{Cu}$ and $\mathrm{MgCu}_{2}$ [53]. Second, the results provide unequivocal evidence that carbon is formed on the surface of $\mathrm{Mg}-\mathrm{Cu}$ alloys, where the reduced carbon atoms would dissolve into the molten metal alloys and nucleate into graphene layers upon saturation inside the molten metal, which then stacks into graphitic domains. 

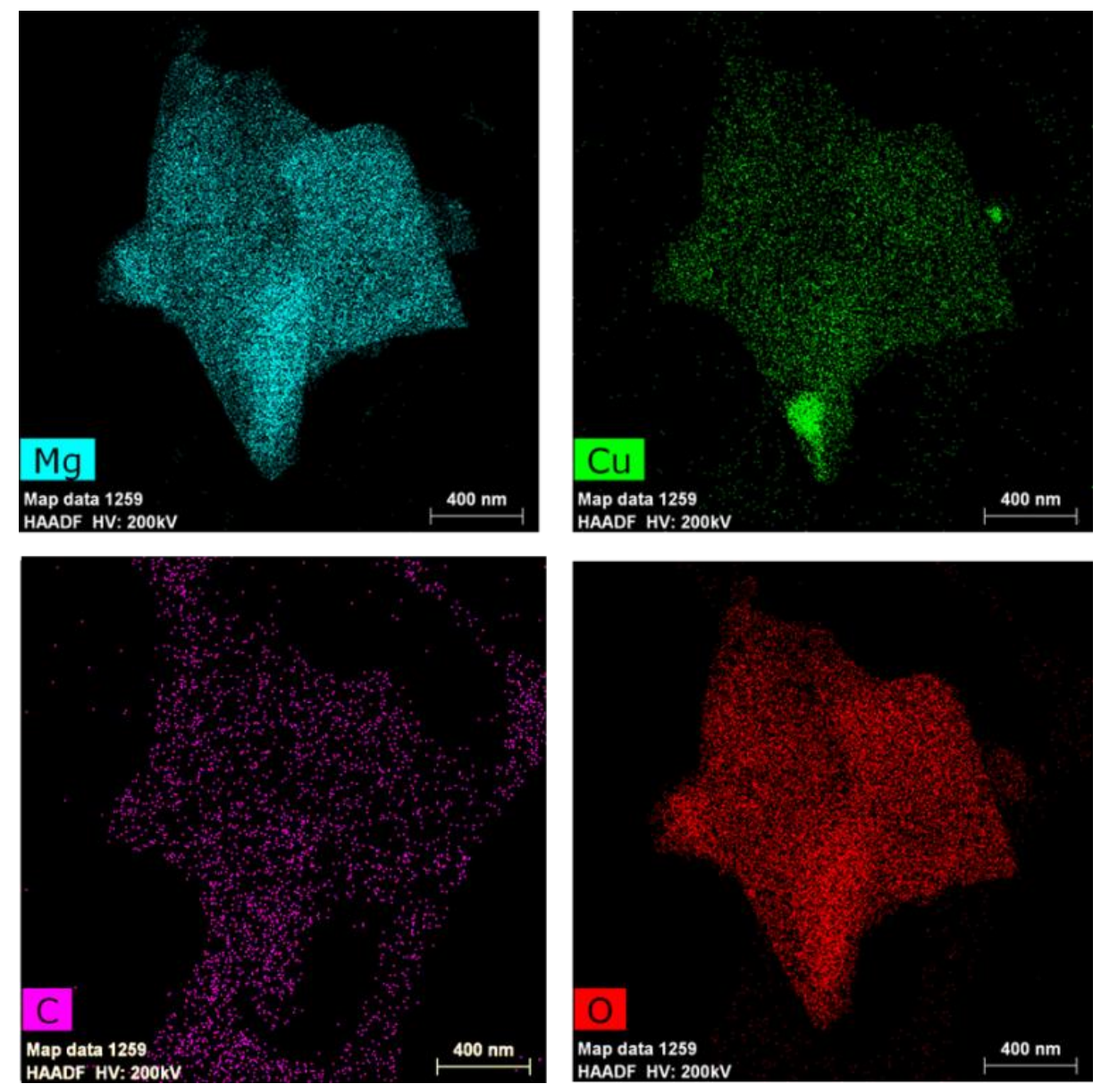

Figure 4. $\mathrm{HAADF}$ Scanning TEM of $\mathrm{C}-\mathrm{Mg} / \mathrm{Cu}$ before $\mathrm{HCl}$ and $\mathrm{NH}_{3} \cdot \mathrm{H}_{2} \mathrm{O}$ etching.

We compared the electrochemical properties of $\mathrm{C}-\mathrm{Mg}$ and $\mathrm{C}-\mathrm{Mg} / \mathrm{Cu}$ as cathode catalysts in MFCs. Linear sweep voltammetry (LSV) results (Figure 5a) show that $\mathrm{C}-\mathrm{Mg} / \mathrm{Cu}$ cathode exhibits a higher current density as much as $279 \%$ of that by $\mathrm{C}-\mathrm{Mg}$ cathode (2.84 vs. $1.02 \mathrm{~A} / \mathrm{m}^{2}$ at $0 \mathrm{~V}$ vs. $\left.\mathrm{Ag} / \mathrm{AgCl}\right)$ over a typical MFC cathode operation potential window from $-0.05 \mathrm{~V}$ to $0.1 \mathrm{~V}$ (v.s. $\mathrm{Ag} / \mathrm{AgCl}$ ). Note that the LSV test was conducted in abiotic cells and the test focused only on the cathode performance. The comparative studies between cathode $\mathrm{C}-\mathrm{Mg}$ and $\mathrm{C}-\mathrm{Mg} / \mathrm{Cu}$ were also performed in MFCs, where the two types of cathode were put in MFC reactors 
fed with growth medium, and assessed by a polarization curve (Figure $\mathbf{5 b}$ to $\mathbf{5 d}$ ). In general, the anode potentials of the two MFCs are similar under the same current densities in Figure 5b, but the $\mathrm{C}-\mathrm{Mg} / \mathrm{Cu}$ cathode exhibited higher operation potentials across the tested current density range, and an overall increase in cell voltage is also obtained in Figure 5c. These results indicate that the increased cell voltages are caused by improved cathode performance, not by the varying anode performances. The $\mathrm{C}-\mathrm{Mg} / \mathrm{Cu}$ cathode also achieved greater power density than the $\mathrm{C}-\mathrm{Mg}$ cathode under the same tested current densities, and $6.2 \%$ enhancement in the max power output (Figure 5d), which indicates that the $\mathrm{C}-\mathrm{Mg} / \mathrm{Cu}$ cathode has an enhanced ability to generate electrical power in an MFC than the C-Mg cathode.

(a)

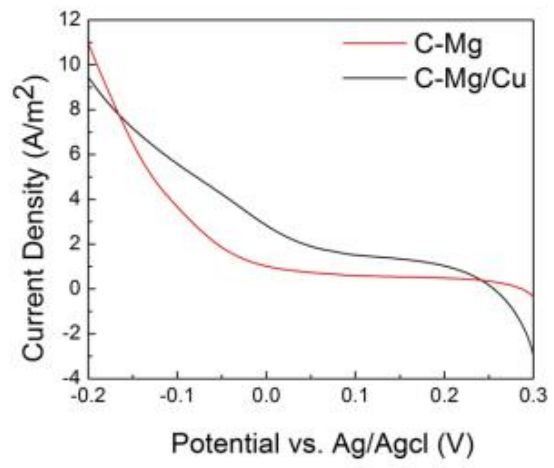

(c)

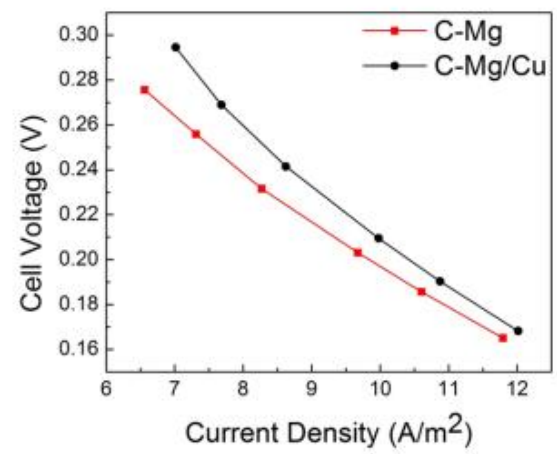

(b)

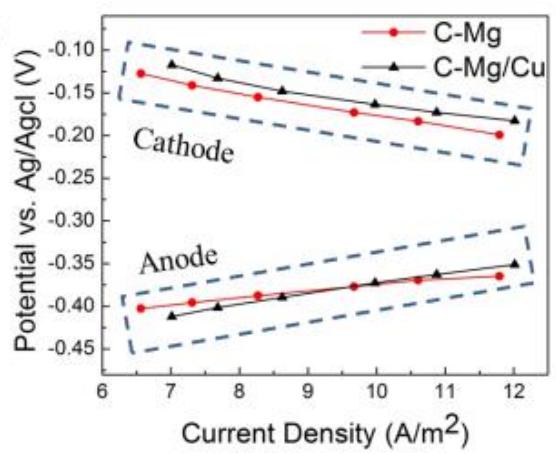

(d)

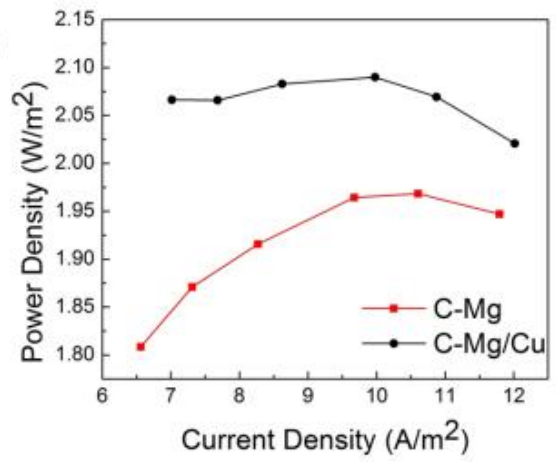

Figure 5. (a) LSV curves of $\mathrm{C}-\mathrm{Mg}$ and $\mathrm{C}-\mathrm{Mg} / \mathrm{Cu}$ cathodes. (b) Individual electrode polarization curves as a function of operating current density for C-Mg and C-Mg/Cu 
cathodes with identical anodes. (c) Full-cell polarization curve with $\mathrm{C}-\mathrm{Mg}$ and C-Mg/Cu cathodes. (d) Power density curves of C-Mg and C-Mg/Cu cathodes.

(a)

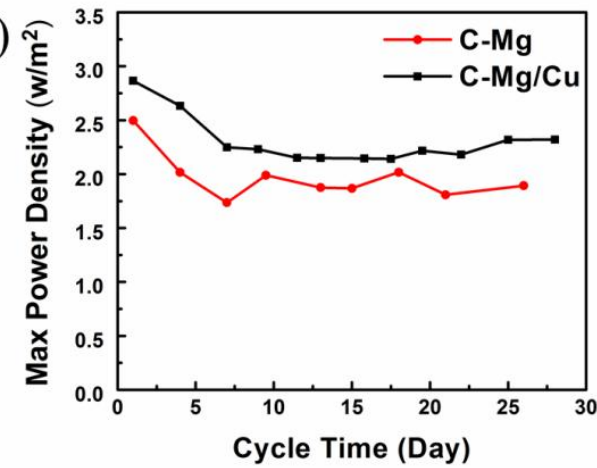

(b)

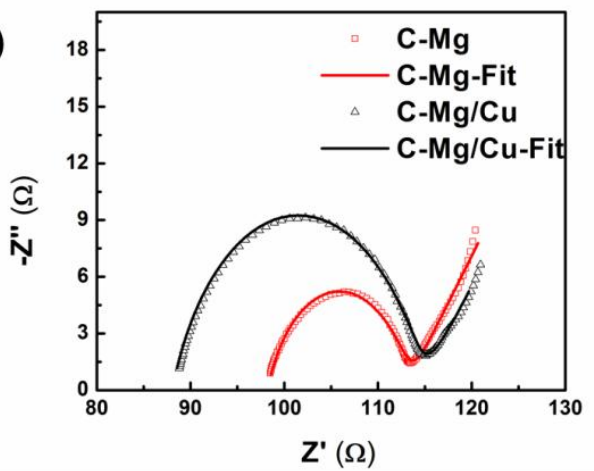

(c)

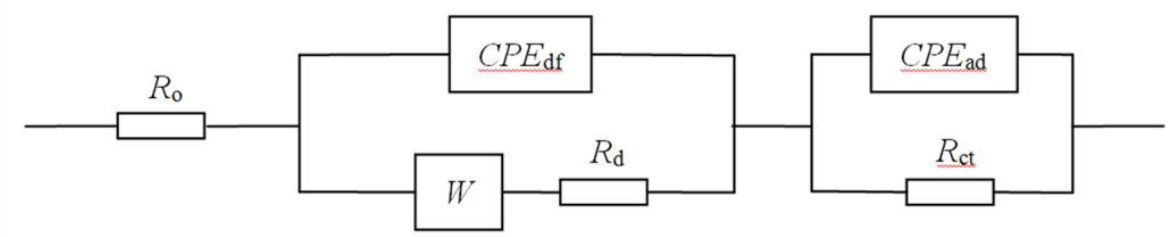

$\mathrm{R}(\mathrm{Q}(\mathrm{WR}))(\mathrm{QR})$

Figure 6. (a) Max power density in each batch of MFC equipped with $\mathrm{C}-\mathrm{Mg} / \mathrm{Cu}$ and C-Mg cathodes. (b) Nyquist plots of $\mathrm{C}-\mathrm{Mg}$ and $\mathrm{C}-\mathrm{Mg} / \mathrm{Cu}$ cathodes. (c) Equivalent circuit of EIS analysis.

The two types of cathodes were also evaluated in MFCs for a month to examine the stability of their performance (Figure 6a). Although both MFCs showed decrease of max power density initially, their performance tended to be stabilized after the first three batches. The $\mathrm{C}-\mathrm{Mg} / \mathrm{Cu}$ cathode generated more significant power than the $\mathrm{C}-\mathrm{Mg}$ cathode during the testing period, and is $21 \%$ higher by the end of 30 days' operation. This clearly demonstrates that both types of cathodes can generate stable 
power output in $\mathrm{MFCs}$ and $\mathrm{C}-\mathrm{Mg} / \mathrm{Cu}$ with enhanced crystallinity showed more preferable properties from the power generation perspective.

Electrochemical impedance spectroscopy (EIS) analysis of the two types of cathode materials was conducted to evaluate the resistance distribution. The high frequency region was interpreted with an equivalent circuit, as previously described (Figure 6c), which includes ohmic resistance $\left(\mathrm{R}_{0}\right)$, diffusion resistance $\left(\mathrm{R}_{\mathrm{d}}\right)$, charge transfer resistance $\left(\mathrm{R}_{\mathrm{ct}}\right)$, Warburg impedance $(W)$, double layer capacitance $\left(\mathrm{CPE}_{\mathrm{df}}\right)$, and pore adsorption capacitance $\left(\mathrm{CPE}_{\mathrm{ad}}\right)$ [54]. The Nyquist plots for the measured and fitted curves and parameter values are shown in Figure $\mathbf{6 b}$, and Table 1 . The $\mathrm{R}_{0}$ of $\mathrm{C}-\mathrm{Mg} / \mathrm{Cu}$ cathode is lower than that of $\mathrm{C}-\mathrm{Mg}$ cathode, which can be attributed to the higher conductivity from the enhanced crystallinity of $\mathrm{C}-\mathrm{Mg} / \mathrm{Cu}$ because the whole cell set-up is the same except for the carbon electrodes. The wider semicircle of the $\mathrm{C}-\mathrm{Mg} / \mathrm{Cu}$ may have to do with the less porosity as well as the smaller pore size, as shown in Figure 3. This explanation has been highlighted in the manuscript. The higher conductivity of $\mathrm{C}-\mathrm{Mg} / \mathrm{Cu}$ well agrees with the larger domain size, as estimated from XRD and Raman results. The significantly lower diffusion resistance $\left(\mathrm{R}_{\mathrm{d}}\right)$ and Warburg impedance of the $\mathrm{C}-\mathrm{Mg} / \mathrm{Cu}$ cathode was possibly due to the increased proton diffusion caused by the enhanced crystallinity, which further increased the cathode performance. The higher $\mathrm{R}_{\mathrm{ct}}$ and lower $\mathrm{CPE}_{\mathrm{ad}}$ of $\mathrm{C}-\mathrm{Mg} / \mathrm{Cu}$ cathode may result from the lower specific surface area and need further study. 
Table 1. Fitting results based on equivalent circuit.

\begin{tabular}{|c|c|c|c|c|c|c|c|c|}
\hline & \multirow{2}{*}{$\mathrm{R}_{0}$} & \multicolumn{2}{|l|}{$\mathrm{CPE}_{\mathrm{df}}$} & \multirow{2}{*}{$\mathrm{R}_{\mathrm{d}}$} & \multirow{2}{*}{$W$} & \multicolumn{2}{|l|}{$\mathrm{CPE}_{\mathrm{ad}}$} & \multirow{2}{*}{$\mathrm{R}_{\mathrm{ct}}$} \\
\hline & & $\mathrm{Q}_{1}$ & $\mathrm{n}_{1}$ & & & $\mathrm{Q}_{2}$ & $\mathrm{n}_{2}$ & \\
\hline $\mathrm{C}-\mathrm{Mg}$ & 98.21 & 0.07411 & 0.5189 & 165.6 & 107.6 & $99.08 \mathrm{e}-6$ & 0.7654 & 14.88 \\
\hline $\mathrm{C}-\mathrm{Mg} / \mathrm{Cu}$ & 88.06 & 0.05447 & 0.6399 & 7.262 & 11.34 & $67.52 \mathrm{e}-6$ & 0.7684 & 26.61 \\
\hline
\end{tabular}

\section{Conclusion}

In summary, we have synthesized porous graphite with high level of crystallinity by adding copper into the magnesiothermic reaction. The analyses based on the XRD, Raman Spectroscopy and HRTEM reveal that copper in the magnesiothermic reaction may play a similar catalytic role as it does in the CVD process in forming graphene layers. Our work advances the capability of magnesiothermic reactions in forming new carbon materials. Furthermore, we revealed that a more crystalline carbon with a good surface area as a cathode promotes the electrochemical activity in terms of the power density of MFCs under neutral $\mathrm{pH}$ conditions. This study provides critical insights for MFCs carbon catalyst selection.

\section{Acknowledgements}

X. J. gratefully acknowledges the financial support from US National Science Foundation, Award No.1551693. H. L. acknowledges the financial support from the US National Science Foundation (IIP 1448986). We are thankful to Professor 
Chih-Hung Chang and Mr. Changqing Pan for Raman spectroscopy. We would like to thank Dr. Peter Eschbach and Ms. Teresa Sawyer for the TEM measurements at the OSU Electron Microscopy Facility. We thank Mr. Joshua Razink for the TEM measurements at CAMCOR.

\section{References}

[1] H. Liu, R. Ramnarayanan, B.E. Logan, Production of electricity during wastewater treatment using a single chamber microbial fuel cell, Environmental science \& technology 38(7) (2004) 2281-2285.

[2] W. Wu, F. Yang, X. Liu, L. Bai, Influence of substrate on electricity generation of Shewanella loihica PV-4 in microbial fuel cells, Microbial cell factories 13(1) (2014) $1-6$.

[3] Y.-C. Song, K.S. Yoo, S.K. Lee, Surface floating, air cathode, microbial fuel cell with horizontal flow for continuous power production from wastewater, J Power Sources 195(19) (2010) 6478-6482.

[4] W. Wu, K.L. Lesnik, S. Xu, L. Wang, H. Liu, Impact of tobramycin on the performance of microbial fuel cell, Microbial cell factories 13(1) (2014) 1-7.

[5] S. Oh, B. Min, B.E. Logan, Cathode performance as a factor in electricity generation in microbial fuel cells, Environmental science \& technology 38(18) (2004) 4900-4904. 
[6] S. You, Q. Zhao, J. Zhang, J. Jiang, S. Zhao, A microbial fuel cell using permanganate as the cathodic electron acceptor, J Power Sources 162(2) (2006) 1409-1415.

[7] H. Liu, B.E. Logan, Electricity generation using an air-cathode single chamber microbial fuel cell in the presence and absence of a proton exchange membrane, Environmental science \& technology 38(14) (2004) 4040-4046.

[8] Y.-C. Song, J.-H. Woo, K. Yoo, J.-W. Chung, C.-Y. Lee, Dual layered CNT structure air cathode for power generation from microbial fuel cells, KSCE Journal of Civil Engineering 17(4) (2013) 646-650.

[9] S. Cheng, H. Liu, B.E. Logan, Power densities using different cathode catalysts (Pt and CoTMPP) and polymer binders (Nafion and PTFE) in single chamber microbial fuel cells, Environmental science \& technology 40(1) (2006) 364-369.

[10] E. HaoYu, S. Cheng, K. Scott, B. Logan, Microbial fuel cell performance with non-Pt cathode catalysts, J Power Sources 171(2) (2007) 275-281.

[11] F. Zhao, F. Harnisch, U. Schröder, F. Scholz, P. Bogdanoff, I. Herrmann, Application of pyrolysed iron (II) phthalocyanine and CoTMPP based oxygen reduction catalysts as cathode materials in microbial fuel cells, Electrochem Commun 7(12) (2005) 1405-1410.

[12] S. Freguia, K. Rabaey, Z. Yuan, J. Keller, Non-catalyzed cathodic oxygen reduction at graphite granules in microbial fuel cells, Electrochim Acta 53(2) (2007) 598-603. 
[13] Y.-C. Song, T.-S. Choi, J.-H. Woo, K. Yoo, J.-W. Chung, C.-Y. Lee, B.G. Kim, Effect of the oxygen reduction catalyst loading method on the performance of air breathable cathodes for microbial fuel cells, Journal of Applied Electrochemistry 42(6) (2012) 391-398.

[14] L. Xiao, J. Damien, J. Luo, H.D. Jang, J. Huang, Z. He, Crumpled graphene particles for microbial fuel cell electrodes, J Power Sources 208 (2012) 187-192.

[15] F. Zhang, S. Cheng, D. Pant, G. Van Bogaert, B.E. Logan, Power generation using an activated carbon and metal mesh cathode in a microbial fuel cell, Electrochem Commun 11(11) (2009) 2177-2179.

[16] H. Dong, H. Yu, X. Wang, Q. Zhou, J. Feng, A novel structure of scalable air-cathode without Nafion and Pt by rolling activated carbon and PTFE as catalyst layer in microbial fuel cells, Water research 46(17) (2012) 5777-5787.

[17] F. Cheng, J. Chen, Metal-air batteries: from oxygen reduction electrochemistry to cathode catalysts, Chem Soc Rev 41(6) (2012) 2172-2192.

[18] D.U. Lee, H.W. Park, M.G. Park, V. Ismayilov, Z. Chen, Synergistic bifunctional catalyst design based on perovskite oxide nanoparticles and intertwined carbon nanotubes for rechargeable zinc-air battery applications, ACS applied materials \& interfaces 7(1) (2014) 902-910.

[19] Y. Liu, D.C. Higgins, J. Wu, M. Fowler, Z. Chen, Cubic spinel cobalt oxide/multi-walled carbon nanotube composites as an efficient bifunctionalelectrocatalyst for oxygen reaction, Electrochem Commun 34 (2013) 125-129. 
[20] S. Peng, L. Li, X. Han, W. Sun, M. Srinivasan, S.G. Mhaisalkar, F. Cheng, Q. Yan, J. Chen, S. Ramakrishna, Cobalt sulfide nanosheet/graphene/carbon nanotube nanocomposites as flexible electrodes for hydrogen evolution, Angewandte Chemie 126(46) (2014) 12802-12807.

[21] Y. Shao, J. Liu, Y. Wang, Y. Lin, Novel catalyst support materials for PEM fuel cells: current status and future prospects, J Mater Chem 19(1) (2008) 46-59.

[22] V.J. Watson, C. Nieto Delgado, B.E. Logan, Influence of chemical and physical properties of activated carbon powders on oxygen reduction and microbial fuel cell performance, Environmental science \& technology 47(12) (2013) 6704-6710.

[23] S. Zhang, L. Chen, S. Zhou, D. Zhao, L. Wu, Facile synthesis of hierarchically ordered porous carbon via in situ self-assembly of colloidal polymer and silica spheres and its use as a catalyst support, Chem Mater 22(11) (2010) 3433-3440.

[24] M.E. Ramos, P.R. Bonelli, A.L. Cukierman, Physico-chemical and electrical properties of activated carbon cloths: effect of inherent nature of the fabric precursor, Colloids and Surfaces A: Physicochemical and Engineering Aspects 324(1) (2008) 86-92.

[25] B. Partoens, F. Peeters, From graphene to graphite: Electronic structure around the K point, Physical Review B 74(7) (2006) 075404-075415.

[26] M.D. Stoller, S. Park, Y. Zhu, J. An, R.S. Ruoff, Graphene-based ultracapacitors, Nano Lett 8(10) (2008) 3498-3502.

[27] H. Chang, J. Qin, P. Xiao, Y. Yang, T. Zhang, Y. Ma, Y. Huang, Y. Chen, Highly Reversible and Recyclable Absorption under Both Hydrophobic and 
Hydrophilic Conditions using a Reduced Bulk Graphene Oxide Material, Adv Mater (2016) 3504-3509.

[28] K. Feng, W. Ahn, G. Lui, H.W. Park, A.G. Kashkooli, G. Jiang, X. Wang, X. Xiao, Z. Chen, Implementing an in-situ carbon network in Si/reduced graphene oxide for high performance lithium-ion battery anodes, Nano Energy 19 (2016) 187-197.

[29] W. Gu, G. Yushin, Review of nanostructured carbon materials for electrochemical capacitor applications: advantages and limitations of activated carbon, carbide - derived carbon, zeolite - templated carbon, carbon aerogels, carbon nanotubes, onion - like carbon, and graphene, Wiley Interdisciplinary Reviews: Energy and Environment 3(5) (2014) 424-473.

[30] I.T. Kim, A. Magasinski, K. Jacob, G. Yushin, R. Tannenbaum, Synthesis and electrochemical performance of reduced graphene oxide/maghemite composite anode for lithium ion batteries, Carbon 52 (2013) 56-64.

[31] N.A. Kumar, H.-J. Choi, Y.R. Shin, D.W. Chang, L. Dai, J.-B. Baek, Polyaniline-grafted reduced graphene oxide for efficient electrochemical supercapacitors, Acs Nano 6(2) (2012) 1715-1723.

[32] Z. Li, S. Wu, W. Lv, J.J. Shao, F. Kang, Q.H. Yang, Graphene Emerges as a Versatile Template for Materials Preparation, Small 12(20) (2016) 2674-2688.

[33] W. Lv, Z. Li, Y. Deng, Q.-H. Yang, F. Kang, Graphene-based materials for electrochemical energy storage devices: opportunities and challenges, Energy Storage Materials 2 (2016) 107-138. 
[34] M.S. Romano, N. Li, D. Antiohos, J.M. Razal, A. Nattestad, S. Beirne, S. Fang, Y. Chen, R. Jalili, G.G. Wallace, Carbon nanotube-reduced graphene oxide composites for thermal energy harvesting applications, Adv Mater 25(45) (2013) 6602-6606.

[35] Y. Shao, J. Wang, H. Wu, J. Liu, I.A. Aksay, Y. Lin, Graphene based electrochemical sensors and biosensors: a review, Electroanalysis 22(10) (2010) 1027-1036.

[36] Y. Shao, S. Zhang, M.H. Engelhard, G. Li, G. Shao, Y. Wang, J. Liu, I.A. Aksay, Y. Lin, Nitrogen-doped graphene and its electrochemical applications, J Mater Chem $20(35)(2010)$ 7491-7496.

[37] Y. Xue, L. Zhu, H. Chen, J. Qu, L. Dai, Multiscale patterning of graphene oxide and reduced graphene oxide for flexible supercapacitors, Carbon 92 (2015) 305-310.

[38] L. Feng, Y. Chen, L. Chen, Easy-to-operate and low-temperature synthesis of gram-scale nitrogen-doped graphene and its application as cathode catalyst in microbial fuel cells, Acs Nano 5(12) (2011) 9611-9618.

[39] S. Li, Y. Hu, Q. Xu, J. Sun, B. Hou, Y. Zhang, Iron-and nitrogen-functionalized graphene as a non-precious metal catalyst for enhanced oxygen reduction in an air-cathode microbial fuel cell, J Power Sources 213 (2012) 265-269.

[40] Z. Xing, B. Wang, J.K. Halsted, R. Subashchandrabose, W.F. Stickle, X. Ji, Direct fabrication of nanoporous graphene from graphene oxide by adding a gasification agent to a magnesiothermic reaction, Chem Commun 51(10) (2015) 1969-1971. 
[41] Z. Xing, B. Wang, W. Gao, C. Pan, J.K. Halsted, E.S. Chong, J. Lu, X. Wang, W. Luo, C.-H. Chang, Reducing CO 2 to dense nanoporous graphene by $\mathrm{Mg} / \mathrm{Zn}$ for high power electrochemical capacitors, Nano Energy 11 (2015) 600-610.

[42] Z. Chen, W. Ren, L. Gao, B. Liu, S. Pei, H.-M. Cheng, Three-dimensional flexible and conductive interconnected graphene networks grown by chemical vapour deposition, Nat Mater 10(6) (2011) 424-428.

[43] J. Coraux, A.T. N'Diaye, C. Busse, T. Michely, Structural coherency of graphene on Ir (111), Nano Lett 8(2) (2008) 565-570.

[44] L. Gao, W. Ren, H. Xu, L. Jin, Z. Wang, T. Ma, L.-P. Ma, Z. Zhang, Q. Fu, L.-M. Peng, Repeated growth and bubbling transfer of graphene with millimetre-size single-crystal grains using platinum, Nat Commun 3 (2012) 699-706.

[45] L. Gao, W. Ren, J. Zhao, L.-P. Ma, Z. Chen, H.-M. Cheng, Efficient growth of high-quality graphene films on $\mathrm{Cu}$ foils by ambient pressure chemical vapor deposition, Appl Phys Lett 97(18) (2010) 183109-183112.

[46] P.W. Sutter, J.-I. Flege, E.A. Sutter, Epitaxial graphene on ruthenium, Nat Mater 7(5) (2008) 406-411.

[47] Y. Liu, J. Xue, T. Zheng, J. Dahn, Mechanism of lithium insertion in hard carbons prepared by pyrolysis of epoxy resins, Carbon 34(2) (1996) 193-200.

[48] C. Hu, S. Sedghi, A. Silvestre-Albero, G.G. Andersson, A. Sharma, P. Pendleton, F. Rodriguez-Reinoso, K. Kaneko, M.J. Biggs, Raman spectroscopy study of the transformation of the carbonaceous skeleton of a polymer-based nanoporous carbon along the thermal annealing pathway, Carbon 85 (2015) 147-158. 
[49] A.C. Ferrari, D.M. Basko, Raman spectroscopy as a versatile tool for studying the properties of graphene, Nat Nanotechnol 8(4) (2013) 235-246.

[50] L.G. Cancado, K. Takai, T. Enoki, M. Endo, Y.A. Kim, H. Mizusaki, A. Jorio, L.N. Coelho, R. Magalhaes-Paniago, M.A. Pimenta, General equation for the determination of the crystallite size L-a of nanographite by Raman spectroscopy, Appl Phys Lett 88(16) (2006) 163106-163106.

[51] M.B. Vázquez-Santos, E. Geissler, K. László, J.-N. Rouzaud, A. Martínez-Alonso, J.M. Tascón, Comparative XRD, Raman, and TEM study on graphitization of PBO-derived carbon fibers, The Journal of Physical Chemistry C 116(1) (2011) 257-268.

[52] C. Mattevi, H. Kim, M. Chhowalla, A review of chemical vapour deposition of graphene on copper, J Mater Chem 21(10) (2011) 3324-3334.

[53] M. Gupta, W. Wong, Magnesium-based nanocomposites: Lightweight materials of the future, Materials Characterization 105 (2015) 30-46.

[54] X. Wang, N. Gao, Q. Zhou, H. Dong, H. Yu, Y. Feng, Acidic and alkaline pretreatments of activated carbon and their effects on the performance of air-cathodes in microbial fuel cells, Bioresource technology 144 (2013) 632-636. 

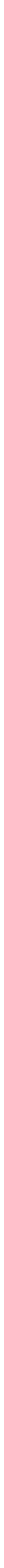

.

. 